\title{
A technical report on repair of amalgam-dentin complex
}

\author{
Özcan, M ; Salihoğlu-Yener, E
}

\begin{abstract}
This clinical report describes a repair protocol for cusp fracture of a failed amalgam-dentin complex. A maxillary right first premolar with an amalgam restoration presented a buccal cusp fracture. Chairside repair has been undertaken by conditioning the existing amalgam restoration with silica coating (30 $\mu$ m CoJet ${ }^{\circledR}-$ Sand), phosphoric acid etching the beveled enamel surface, priming dentin, and application of a bonding agent on both enamel and dentin. Thereafter, the amalgam was silanized (ESPE®-Sil), and opaque resin was applied and polymerized to mask the amalgam. The fractured buccal cusp was modeled using resin composite (Clearfil Photo Posterior) and photo-polymerized. Finally, the amalgam was refinished and refurbished and the composite was finished and polished.
\end{abstract}

DOI: https://doi.org/10.2341/10-359-T

Posted at the Zurich Open Repository and Archive, University of Zurich ZORA URL: https://doi.org/10.5167/uzh-58748

Journal Article

Published Version

Originally published at:

Özcan, M; Salihoğlu-Yener, E (2011). A technical report on repair of amalgam-dentin complex. Operative Dentistry, 36(5):563-566.

DOI: https://doi.org/10.2341/10-359-T 


\title{
Clinical Technique/Case Report
}

\section{A Technical Report on Repair of Amalgam-dentin Complex}

\author{
M Özcan • E Salihoğlu-Yener
}

\section{Clinical Relevance}

The improved adhesive technologies for surface conditioning of restorative materials and dental tissues give the opportunity for repairing cusp fractures next to amalgam restorations without necessitating any extensive and costly therapy options.

\section{SUMMARY}

This clinical report describes a repair protocol for cusp fracture of a failed amalgam-dentin complex. A maxillary right first premolar with an amalgam restoration presented a buccal cusp fracture. Chairside repair has been undertaken by conditioning the existing amalgam restoration with silica coating $(30 \mu \mathrm{m}$ CoJet ${ }^{\circledR}$-Sand), phosphoric acid etching the beveled enamel surface, priming dentin, and application of a bonding agent on both enamel and dentin. Thereafter, the amalgam was silanized $\left(\mathrm{ESPE}^{{ }-\mathrm{Sil}}\right)$, and opaque resin was applied and polymerized to mask the amalgam. The fractured buccal cusp was modeled using resin composite (Clearfil Photo Posterior) and

\footnotetext{
*Mutlu Özcan, DrMedDent, PhD, professor and research associate, University of Zurich, Center for Dental and Oral Medicine, Dental Materials Unit, Clinic for Fixed and Removable Prosthodontics and Dental Materials Science, Zurich, Switzerland

Esra Salihoğlu Yener, DDS, PhD, Yeditepe University, Faculty of Dentistry, Department of Prosthetic Dentistry, Istanbul, Turkey

*Corresponding author: Plattenstrasse 11, CH-8032, Zurich, Switzerland; e-mail: mutluozcan@hotmail.com
}

DOI: $10.2341 / 10-359-\mathrm{T}$ photo-polymerized. Finally, the amalgam was refinished and refurbished and the composite was finished and polished.

\section{INTRODUCTION}

Various materials such as amalgam, resin composite, porcelain, or cast metals have been used for the restoration of missing tooth structure. Among these, amalgam has been the most common material used for posterior teeth for more than a century. It is one of the least technique-sensitive materials with high compressive strength. ${ }^{1}$ Unfortunately, it does not adhere to dental tissues. Cusp fracture of a posterior tooth with an extensive mesio-occlusodistal (MOD) amalgam restoration is a common failure. The MOD cavity preparation causes a loss of $63 \%$ of cuspal rigidity, ${ }^{2}$ and thus occlusal forces can cause fracture of weak cusps. ${ }^{3}$ On the other hand, intact teeth rarely show cusp fracture because the presence of marginal ridges and buccal and palatal cusps generates a circular integrity and thus ensures the strengthening of the tooth. ${ }^{4}$

Traditionally, fractured teeth are restored with a new restoration. However, the current treatment philosophy in dentistry is based on a minimally invasive approach by which intact tooth tissues are conserved as much as possible. Repair of both the 
fractured tooth and the restoration itself could be achieved using surface-conditioning methods, adhesion promoters, and high-strength resin composite materials. Moreover, repairing a restoration is a time-saving process, economical, and conservative.

The new adhesive systems provide greater interfacial strength and fracture resistance and present diminished microleakage. ${ }^{5,6}$ Recently, conditioning techniques have been used to attain an effective bonding of amalgam to tooth structure or to repair amalgam restorations with composite material. ${ }^{7}$ This clinical report describes a repair protocol for cusp fracture of a failed amalgam-dentin complex.

\section{METHODS AND MATERIALS}

A 48-year-old woman presented with a fractured buccal cusp of the maxillary right first premolar (tooth no. 5). The fracture ended supragingivally. The tooth had a problem-free amalgam restoration (Figure 1a). Following detailed clinical examination, repairing the fractured tooth structure with resin composite was considered to be the most quick and economical treatment option for the patient.

The enamel was beveled with a diamond bur (Acurata G $+\mathrm{K}$ Mahnhardt Dental, Thurmansbarg, Germany). Following air-abrasion of the buccal surface of the amalgam restoration using silicacoated alumina particles $\left(30 \mu \mathrm{m} \mathrm{SiO}_{2}\right.$, CoJet ${ }^{\circledR}$-Sand, 3M ESPE AG, Seefeld, Germany) using an intraoral air-abrasion device (Dento-Prep ${ }^{\mathrm{TM}}$, RØNVIG A/S, Daugaard, Denmark) at a pressure of 2.5 bar from a distance of approximately $10 \mathrm{~mm}$ for 5 seconds (Figure 1b), enamel and dentin were etched with $35 \%$ orthophosphoric acid (Ultraetch, Ultradent, South Jordan, UT, USA) for 15 seconds. After rinsing for 10 seconds and air-drying, a 3-methacryloxypropyltrimethoxy silane coupling agent $\left(\mathrm{ESPE}^{{ }^{\circledR}}\right.$ Sil; 3M ESPE AG) was applied on the amalgam and its evaporation awaited for 5 minutes. Afterward, the dentin surface was conditioned with primer (Cavex Sealer, Cavex, Haarlem, The Netherlands) for 15 seconds and gently air-dried. Then, bonding agent (Cavex Unibond, Cavex) was applied on amalgam, enamel, and dentin and photo-polymerized for 20 seconds. In order to mask the amalgam, a thin layer of opaquer (Visiogem, 3M ESPE AG) was applied to the silanized amalgam surface using the tip of a probe, and it was photo-polymerized for 120 seconds (Optilux 501, Kerr, Orange, CA, USA) (Figure 1c). Light intensity of the polymerization device was $450 \mathrm{~mW} / \mathrm{cm}^{2}$ (SDS, Kerr, Orange, CA). Following the bonding procedures, the resin composite (Clearfil Photoposterior, Kuraray, Tokyo, Japan) was adhered to the conditioned amalgam and dental tissues and photo-polymerized for 40 seconds (Figure 1d). Finally, the amalgam was refurbished and refinished. Finishing and polishing procedures were also performed on the resin composite (Figure 1e).

\section{DISCUSSION}

This clinical report describes a conservative and esthetic repair method of fractured cusp of a premolar using adhesive techniques. The developments in adhesion methods offer a conservative, practical, time-saving, and economical approach for the repair of fractured teeth.

Restoring teeth with cusp fractures can be performed by various means. Conventionally, the existing restoration is removed and the decision regarding the restorative material and restoration type is made according to the remaining intact tooth structure. In most situations, the new restoration needs more tooth removal than the existing one. In fact, because a minimally invasive dental application is a current issue of today's dentistry, the improvements in adhesive technologies and in composite
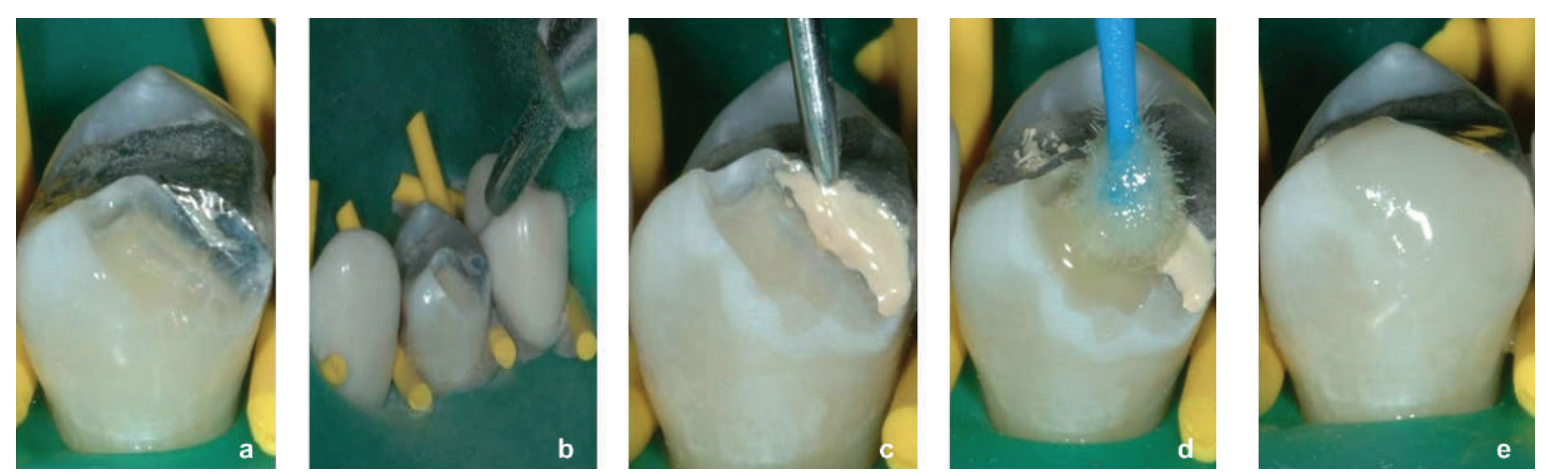

Figure 1. (a): Baseline situation of fractured buccal cusp on maxillary right first premolar (tooth no. 5). (b): Silica-coating of the amalgam surface. (c): Application of the opaquer. (d): Application of the adhesive resin. (e): Final view of the finished restoration. 
materials have enabled clinicians to repair such fractured teeth. Repairing the existing restoration is an economical approach compared with its total replacement. ${ }^{8}$ Moreover, repair preserves tooth structure when the coronal tooth configuration is insufficient.

When restoring cusp fractures, several factors should be considered, one of which is the location of the fracture. It has been reported that in order to prevent subgingival tooth fractures, the remaining sound cusps should be lowered while preparing for a restoration. ${ }^{9}$ If the fracture ends supragingivally and the existing restoration is problem free, it is then possible to consider repair options. ${ }^{10}$

Several techniques based on micromechanical retention and chemical adhesion have been reported in the literature to repair cusp fractures using resin composites. ${ }^{7,11-15}$ Mechanical retention requires preparation of undercuts and grooves, ${ }^{12,14}$ whereas chemical adhesion involves the use of adhesion promoters. ${ }^{14,15}$

Among different conditioning methods to improve the adhesion of intraoral repair systems to amalgam restorations, airborne particle abrasion of the alloy is commonly used prior to bonding procedures. Airabrasion roughens the surface and thus improves the micromechanical retention. ${ }^{16}$ However, there are conflicting results in the literature about the favorable effect of air-abrasion on the bond strength of composite to amalgam. In a study that focused on adhesion of bonded orthodontic attachments to amalgam, surface topography was found to play a more significant role in the bond strength. ${ }^{12}$ The authors concluded that the air-abraded specimens resembled an acid-etched, microporous surface. However, in another study, surface roughening by air-abrasion did not affect the bond strength on the amalgam. $^{7}$

Silica coating is another conditioning method to improve adhesion of resin-based materials to amalgam restorations, where the tribochemical effect of airborne particle abrasion results in deposition of a thin coating on the alloy surface. The subsequent application of a silane coupling agent forms a polysiloxane network on the substrate that in turn reacts with the methacrylate monomers of the opaquer or composite. ${ }^{17}$

Another method for increasing bond strength and fatigue resistance of the adhesive interface is the application of fibers on the conditioned amalgam surface. ${ }^{7,18}$ Additionally, it has been shown that glass fibers can resist tensile stresses and stop crack propagation in composite materials. ${ }^{19}$ In a previous study, a combination of silica coating and silanization with the addition of optional preimpregnated bidirectional E-glass fiber sheets at the adhesive interface significantly increased the bond strength of resin composite to amalgam. ${ }^{7}$ The authors concluded that the bond strength results were higher than the recommended International Organization for Standardization standard and can be considered strong enough for clinical practice. However, in small cusp fractures as presented in this case, the use of a fiber layer was not considered to be necessary. Larger cusp fractures or amalgam defects may benefit from this application.

\section{(Accepted 25 January 2011)}

\section{REFERENCES}

1. Korale ME \& Meiers JC (1996) Microleakage of dentin bonding systems used with spherical and admixed amalgams American Journal of Dentistry 9(6) 249-252.

2. Plotino G, Buono L, Grande NM, Lamorgese V \& Somma F (2008) Fracture resistance of endodontically treated molars restored with extensive composite resin restorations Journal of Prosthetic Dentistry 99(3) 225-232.

3. Hurmuzlu F, Serper A, Siso SH \& Er K (2003) In vitro fracture resistance of root-filled teeth using new-generation dentine bonding adhesives International Endodontic Journal 36(11) 770-773.

4. Sagsen B \& Aslan B (2006) Effect of bonded restorations on the fracture resistance of root filled teeth International Endodontic Journal 39(11) 900-904.

5. Steele A \& Johnson BR (1999) In vitro fracture strength of endodontically treated premolars Journal of Endodontics 25(1) 6-8.

6. Faria AC, Rodrigues RC, de Almeida Antunes RP, de Mattos MD \& Ribeiro RF (2010) Endodontically treated teeth: Characteristics and considerations to restore them Journal of Prosthodontic Research 55(2) 69-74.

7. Özcan M, Vallittu PK, Huysmans MC, Kalk W \& Vahlberg T (2006) Bond strength of resin composite to differently conditioned amalgam Journal of Material Science: Materials in Medicine 17(1) 7-13.

8. Randall RC, Vrijhoef MM \& Wilson NH (2002) Current trends in restorative dentistry in the UK: A Delphi approach Journal of Dentistry 30(4) 177-187.

9. Fennis WM, Kuijs RH, Kreulen CM, Verdonschot N \& Creugers NH (2004) Fatigue resistance of teeth restored with cuspal-coverage composite restorations International Journal of Prosthodontics 17(3) 313-317.

10. Fennis WM, Tezvergil A, Kuijs RH, Lassila LV, Kreulen CM, Creugers NH \& Vallittu PK (2005) In vitro fracture resistance of fiber reinforced cusp-replacing composite restorations Dental Materials 21(6) 565-572.

11. Özcan M \& Vallittu PK (2003) Effect of surface conditioning methods on the bond strength of luting cement to ceramics Dental Materials 19(8) 725-731. 
12. Sperber RL, Watson PA, Rossouw PE \& Sectakof PA (1999) Adhesion of bonded orthodontic attachments to dental amalgam: In vitro study American Journal of Orthodontics and Dentofacial Orthopedics 116(5) 506-513.

13. Özcan M, Pfeiffer P \& Nergiz I (1998) A brief history and current status of metal- and ceramic surface-conditioning concepts for resin bonding in dentistry Quintessence International 29(11) 713-724.

14. Chang JC (2004) Amalgam repair with a 4-META resin Journal of Prosthetic Dentistry 92(5) 506-507.

15. Marshall SJ, Bayne SC, Baier R, Tomsia AP \& Marshall GW (2010) A review of adhesion science Dental Materials 26(2) 11-16.
16. Monticelli F, Osorio R, Sadek FT, Radovic I, Toledano M \& Ferrari M (2008) Surface treatments for improving bond strength to prefabricated fiber posts: A literature review Operative Dentistry 33(3) 346-355.

17. Özcan M (2002) The use of chairside silica coating for different dental applications: A clinical report Journal of Prosthetic Dentistry 87(5) 469-472.

18. Vallittu PK (2002) Use of woven glass fibres to reinforce a composite veneer. A fracture resistance and acoustic emission study Journal of Oral Rehabilitation 29(5) 423-429.

19. Lassila LV, Nohrstrom T \& Vallittu PK (2002) The influence of short-term water storage on the flexural properties of unidirectional glass fiber-reinforced composites Biomaterials 23(10) 2221-2229. 